\title{
Estimating insured residential losses from large flood scenarios on the Tone River, Japan - a data integration approach
}

\author{
T. Okada, K. J. McAneney, and K. Chen \\ Risk Frontiers, Macquarie University, NSW 2109, Australia \\ Received: 16 August 2011 - Accepted: 12 November 2011 - Published: 21 December 2011
}

\begin{abstract}
Flooding on the Tone River, which drains the largest catchment area in Japan and is now home to 12 million people, poses significant risk to the Greater Tokyo Area. In April 2010, an expert panel in Japan, the Central Disaster Prevention Council, examined the potential for largescale flooding and outlined possible mitigation measures in the Greater Tokyo Area. One of the scenarios considered closely mimics the pattern of flooding that occurred with the passage of Typhoon Kathleen in 1947 and would potentially flood some 680000 households above floor level. Building upon that report, this study presents a Geographical Information System (GIS)-based data integration approach to estimate the insurance losses for residential buildings and contents as just one component of the potential financial cost. Using a range of publicly available data - census information, location reference data, insurance market information and flood water elevation data - this analysis finds that insurance losses for residential property alone could reach approximately 1 trillion JPY (US\$ 12.5 billion). Total insurance losses, including commercial and industrial lines of business, are likely to be at least double this figure with total economic costs being much greater again. The results are sensitive to the flood scenario assumed, position of levee failures, local flood depths and extents, population and building heights. The Average Recurrence Interval (ARI) of the rainfall following Typhoon Kathleen has been estimated to be on the order of $200 \mathrm{yr}$; however, at this juncture it is not possible to put an ARI on the modelled loss since we cannot know the relative or joint probability of the different flooding scenarios. It is possible that more than one of these scenarios could occur simultaneously or that levee failure at one point might lower water levels downstream and avoid a failure at all other points. In addition to insurance applications, spatial analyses like that presented here have implications for emergency management, the cost-benefit of mitigation efforts and land-use planning.
\end{abstract}

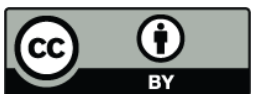

Correspondence to: T. Okada (tetsuya.okada@mq.edu.au)

\section{Introduction}

In developed countries, private sector insurance payouts provide much of the finance needed to fund the recovery after natural disasters. Insured (and economic) losses from natural hazards have been increasing globally (Swiss Re, 2010) and this is expected to continue because of increasing exposure in hazardous locations (Pielke and Landsea, 1998; Pielke et al., 2008; Crompton and McAneney, 2008). This is true of most weather-related natural hazards (Bouwer, 2011), including the focus of our study here: riverine flooding. Although engineering works may reduce losses from otherwise frequent small floods, encouraging development behind levees may amplify losses when these fail in large floods or overtop (Swiss Re, 2007). This will be the case for the Tone River system in the Greater Tokyo Area due to the high population density as well as the accumulation of political and economic infrastructure in these areas (Central Disaster Prevention Council, 2010 - hereafter CDPC2010).

The Tone River system drains the largest catchment in all of Japan (area: $16840 \mathrm{~km}^{2}$ ). The river network has undergone extensive engineering over the last few centuries, significantly altering its routing and flow. The last significant flooding occurred in September 1947 following heavy rainfall induced by the passage of Typhoon Kathleen. The recent CDPC report explores the potential for large scale flooding and possible mitigation actions in the Greater Tokyo Area. To establish the cost-benefit analysis of any risk mitigation measures, we must first understand the scale of the likely losses with and without such measures. The Tone River Upstream Office (2011) suggests that if the levees were to be breached by another typhoon with similar physical attributes to Typhoon Kathleen, then the financial damage to general assets, agricultural products and other items could reach 34 trillion JPY (US\$ 425 billion), but provides no detail as to the provenance of this figure. Our study seeks to estimate the insurance losses due to damage to residential dwellings and contents arising from different flooding scenarios for the Tone River.

Published by Copernicus Publications on behalf of the European Geosciences Union. 
Flood risk assessment has been an active research field across the world over the past few decades, but attention is often biased towards the hazard component alone (e.g. magnitudes and probabilities of flood events) (see Merz et al., 2010 for a comprehensive review). The authors believe that more efforts should be made to improve the methodology of flood damage assessment, including the collection of flood damage data for model validation and the adoption of spatially-explicit GIS approaches (Downton et al., 2005; Sanders et al., 2005; Forte et al., 2006; Fedeski et al., 2007; Luino et al., 2009; Merz et al., 2010). The HAZUS Flood Model, which integrates various inputs with the GIS technology, has been developed in the United States to estimate direct and indirect damages, including economic losses in flood risk (Scawthorn et al., 2006a, b). In Japan, Kondo (2005) has also stressed the importance of GIS methodologies in examining local-level data for flood risk mitigation, while Okazaki (2009) highlighted the necessity of risk assessment through GIS-based flood simulations with information beyond hazard maps in order to effectively mitigate damage to business activities.

Our study employs a GIS-based data integration approach and examines likely losses in the form of insured losses to residential property as one component of the economic costs arising from a recurrence of a flooding event on the Tone River like that which occurred in September 1947. In doing so, we first estimate numbers of households likely to be impacted and the likely depths of flooding, and then apply common insurance policy provisions in Japan. Total insured losses will also include those due to commercial and industrial lines of business and economic losses will be greater again.

The study begins with a description of the Tone River, and reviews previous studies and official reports that have described the engineered eastward diversion of the river, its levee system and the flooding that arose from Typhoon Kathleen. This is followed by sections detailing our loss estimation methodology, which employs spatial analyses and insurance payout structures for residential property, discussion of salient results and their implications for mitigation before concluding with some limitations of our approach.

\section{Tone River system}

The Tone River is one of the major rivers in Japan, and flows across the Kanto plain from northwest to southeast through the northern part of the Greater Tokyo Area. It is the second longest river in the country and its catchment area, which spans seven prefectures - Tokyo, Gunma, Chiba, Ibaraki, Tochigi, Saitama and Nagano - is $16840 \mathrm{~km}^{2}$, the largest in Japan (Fig. 1). Approximately 12 million residents live within the catchment and a large part of this population lives in the downstream area (Tone River Upstream Office, 2011).

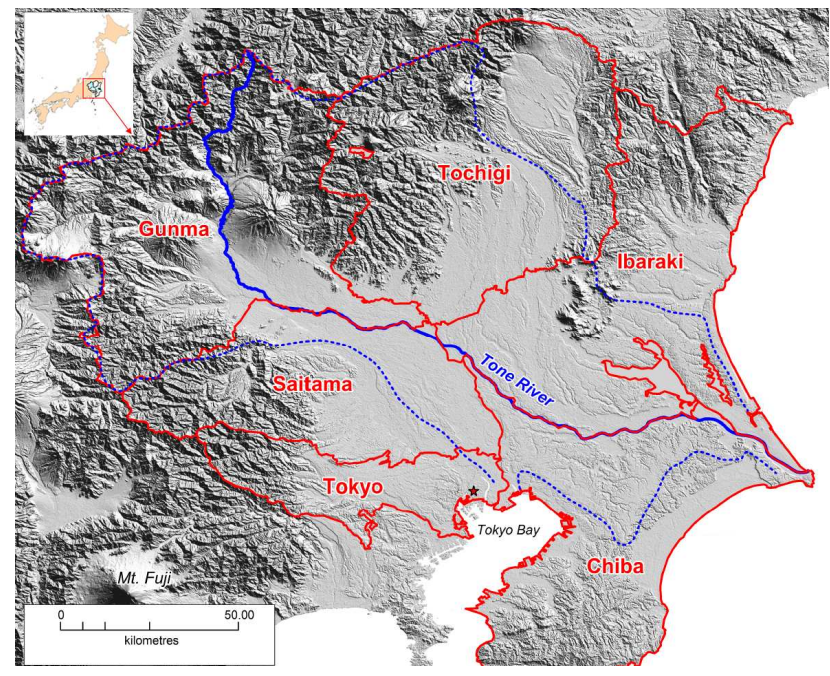

Fig. 1. Tone River and its catchment boundary with surrounding prefectures. Tone River is indicated by the bold blue line. The catchment boundary of Tone River is depicted by the dotted blue line. The red star within the Tokyo Metropolitan Area represents central Tokyo.

The catchment represents around $4.5 \%$ of the total land area of Japan (Tone River Upstream Office, 2011).

\subsection{Eastward diversion of Tone River}

According to the National Research Institute for Earth Science and Disaster Prevention (2011), prior to the Edo Period, which began in 1603, the Tone, Watarase and Ara Rivers all flowed southwards into Tokyo Bay, while the Kinu, Hitachi and Kokai Rivers flowed towards Kashima Bay in a southeasterly direction, dividing the Kanto Plain into two catchments. From the end of 16th century, the Tokugawa Shogunate, which established its base in Edo (current day Tokyo), began large scale construction works by building a series of river channels that diverted the Tone River eastward (Fig. 2). The diversion aimed to create a shipping route, develop new rice fields and protect Edo from floods.

The diversion comprised a number of construction phases undertaken more than $350 \mathrm{yr}$ (Saito, 2006). Firstly, the middle part of Tone River was confined into a single channel. Then the Shinkawadori channel was constructed to connect the Tone and Watarase Rivers. Following this, the Akahori River was created through the upland zone that was formerly the catchment boundary of the plain to connect the Tone River to the Hitachi River. Other major works included cutting the channel upstream of the Edo River; disconnecting the Kinu and Kokai Rivers; and connecting the Ara River, which used to be a tributary of the Tone River, to the Iruma River. With further engineering works, the river path shifted eastwards, forming what is now the main stream of the Tone River. However, despite these efforts to control its flow, the 

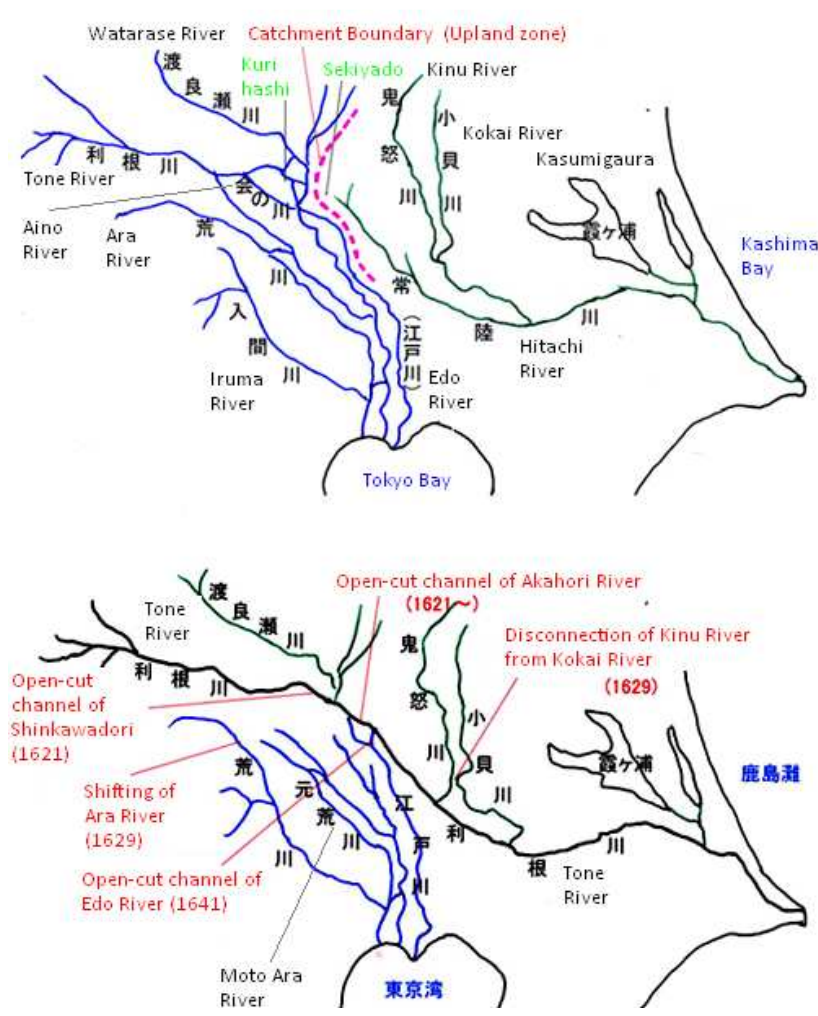

Fig. 2. Diversion of streams in the Tone River catchment (modified from Tone River Research Group (1995) as cited in the National Research Institute for Earth Science and Disaster Prevention Report, 2011). The top map shows the original configuration and the bottom the current system.

middle section of the Tone River has repeatedly flooded with as many as 16 large-scale floods recorded since 1700 (National Research Institute for Earth Science and Disaster Prevention, 2011).

Levees have been repeatedly constructed on the Tone River. These levees are mainly constructed of compacted soil; and due to the significant variability of soil strength when saturated, it is very difficult to analyse and estimate their performance (Nakajima, 2004), which may be further deteriorated by leakage. This uncertainty explains the large number of potential flood scenarios conducted by the Tone River Upstream Office, which will be described in later discussion (see Methodology section).

\subsection{Impacts of Typhoon Kathleen 1947}

Flooding arising from the passage of Typhoon Kathleen caused enormous damage in the Kanto region in September 1947, including the loss of 1100 lives, the inundation of 303160 houses and financial damage (in the monetary value of the day) of JPY 7 billion (Tone River Upstream Office, 2011). According to Saito (2006), the typhoon was spawned east of the Mariana Islands on the 8 September and its track

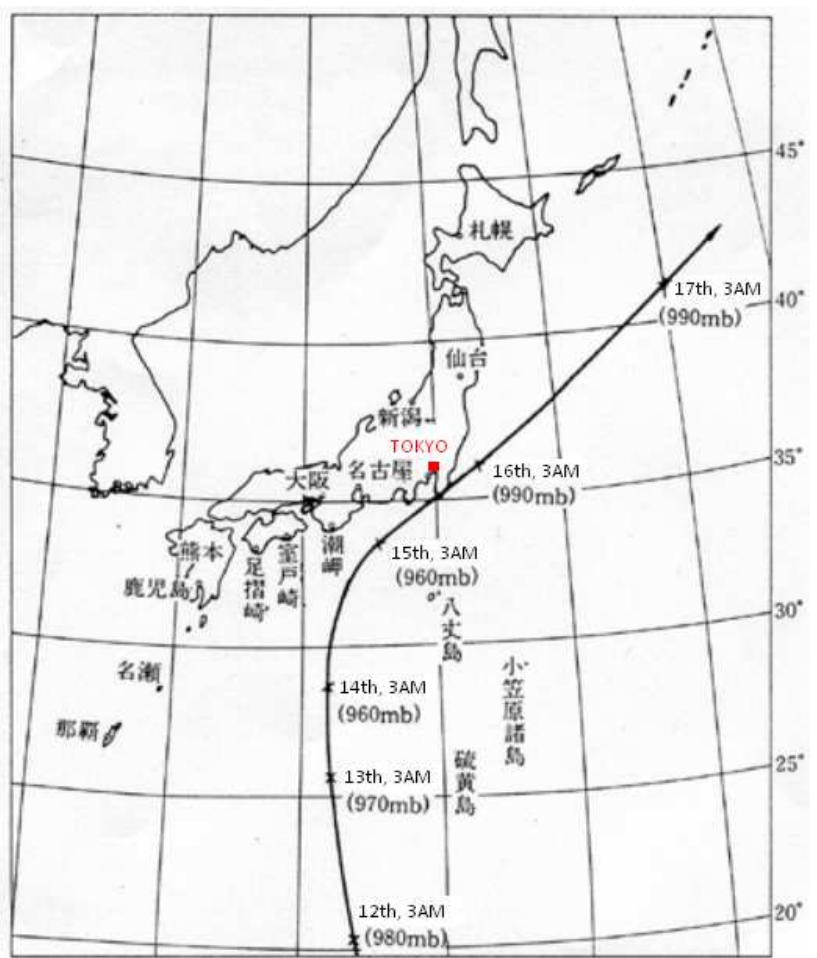

Fig. 3. Track of Typhoon Kathleen (modified from Kanto Regional Development Bureau, Ministry of Land, Infrastructure, Transport and Tourism, 2011).

passed Tori Island early on the 14th, the Kii Peninsula early on the 15th and the southern part of Boso Peninsula in the evening of the same day, before moving out to sea off Sanriku (Fig. 3).

Although the typhoon did not make landfall, it stimulated a rain front that had already stalled over Honshu Island and caused heavy rainfall in the Kanto and Tohoku regions (Saito, 2006; National Research Institute for Earth Science and Disaster Prevention, 2011). In the Tone River catchment, the total three-day rainfall (13 to 15 September) averaged $318 \mathrm{~mm}$ over the basin above Yattajima and $300 \mathrm{~mm}$ or more in most tributary basins in the same catchment area, causing the highest runoff levels ever recorded in Japan (Cabinet Office, 2006). In the Shinkawadori channel, the Tone River overtopped the levee by $0.5 \mathrm{~m}$ for $1300 \mathrm{~m}$, leading to the eventual collapse of $350 \mathrm{~m}$ of its length (National Research Institute for Earth Science and Disaster Prevention, 2011).

Runoff into the Tone River and its upstream tributaries took the middle section of the main river to its full capacity. The Watarase River also flooded similarly with water backing up from the Tone River. Levees broke at 24 places on the two rivers as well as on other tributaries and branches between the evening of the 15th and early on the 16th. The total length of levee breaks reached $5.9 \mathrm{~km}$. There were two breaches of the Tone River levees: the first, as discussed 
earlier, at Shinkawadori, Otone Town (part of current Kazo City) in Saitama; and the second at Nakagawa, Bando City in Ibaraki. Both occurred in the sections artificially altered in the earlier diversion works (Saito, 2006).

In the major flood that started in Otone Town, water overflowed the right levee $134.4 \mathrm{~km}$ upstream from the river mouth (Tone River Upstream Office, 2011), leaving the engineered channel and reverting to its "natural" flow routing that had existed prior to the diversion (National Research Institute for Earth Science and Disaster Prevention, 2011). The flow, which destroyed the levees of small-to-mid scale rivers on the way, entered the Tokyo Metropolitan Area, and was drained at the mouth of the Edo River. The flooding extended some $60 \mathrm{~km}$ (National Research Institute for Earth Science and Disaster Prevention, 2011), inundating an area of approximately $440 \mathrm{~km}^{2}$ (Tone River Upstream Office, 2011).

The levee-break in the Watarase River also inundated low land located on the northern side of the Shinkawadori channel. The inundation depth in this area reached $6.5 \mathrm{~m}$ due to water retention by the surrounding levees inside the confluence of the two rivers (National Research Institute for Earth Science and Disaster Prevention, 2011).

\section{Methodology}

This study analyses the flood risk in 55 municipalities within six prefectures - Ibaraki: 7, Tochigi: 4, Gunma: 9, Saitama: 29, Chiba: 3, Tokyo: 3, all based on the numbers of administrative districts at the end of 2009 - in line with the designated flood areas in data provided by the Tone River Upstream Office. Several data sets (see below) were integrated in order to assess likely insurance losses for various flooding scenarios on the Tone River. The 51 flood scenarios provided by the Tone River Upstream Office are based on a modelled three-day precipitation total of $318 \mathrm{~mm}$ within the entire basin upstream of Yattajima (area: approximately $5100 \mathrm{~km}^{2}$ ) located on the left bank of the Tone River and $181.5 \mathrm{~km}$ from the river mouth. According to the Tone River Upstream Office (2011), this rainfall amount is considered to have an Average Recurrence Interval (ARI) of approximately $200 \mathrm{yr}$, and is similar to the precipitation caused by Typhoon Kathleen in 1947 (Cabinet Office, 2006).

Our study examines six out of the 51 scenarios considered in the CDPC2010 (Fig. 4). Each is labelled by its levee breach point based on location and distance from the river mouth: for example, R118k5 means the levee-break point is located on the right levee of the river, $118.5 \mathrm{~km}$ upstream from the river mouth.

Primary data sources employed in our study comprise:

- Flood depth mesh data provided by Tone River Upstream Office (2011);

- 2005 Japanese census data (National Statistics Center: www.e-stat.go.jp/SG1/estat/eStatTopPortal.do); and

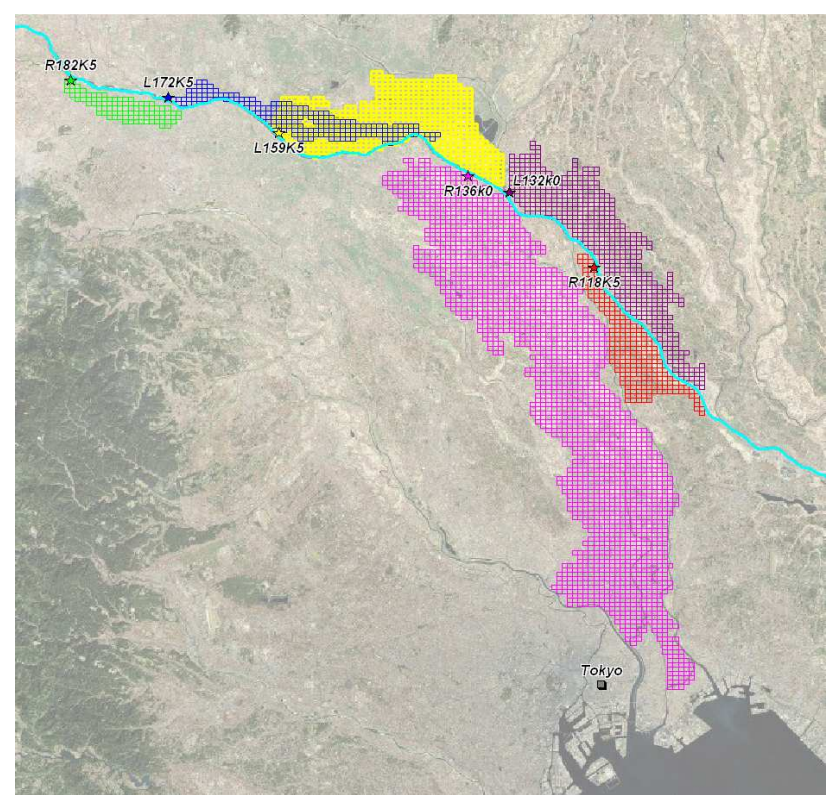

Fig. 4. Flood extents of the selected scenarios in this study: Red: R118k5, Yellow: L159k5, Green: R182k5, Pink: R136k0, Purple: L132k0 and Blue: L172k. Stars: Levee-break points, Gray Square: Central Tokyo, Light blue line: Tone River (L172k5 and L159k5 partially overlap) (adapted from Tone River Upstream Office, National and Regional Planning Bureau).

- 2009 address location reference data (Na-
tional and Regional Planning Bureau:
www.mlit.go.jp/kokudokeikaku/gis/index.html).

\subsection{Integration of flood depth and location reference data sets}

The flood depth data sets provided by the River Office were first transformed into grid maps. Each grid in the depth maps was sized at approximately $500 \mathrm{~m}$. The depth grid data was then overlaid with address location data. Location reference data represents the geographical centroid of each Gaiku level. In the Japanese address system, Gaiku is the finest resolution of freely-available GIS address data in Japan, with several dozen individual addresses normally included in one Gaiku in populated urban areas. The resolution hierarchy of these data generally spans from Gaiku through to Cho/Chome to City/Town/Ward and Prefecture scales. The yellow lines in Fig. 5 show Cho/Chome boundaries that form the entire Katsushika Ward in Tokyo. The pink dots in the right hand figure represent each Gaiku within Cho/Chome areas. The flood depth values were extracted to the Gaiku points by overlaying them in a GIS framework. 


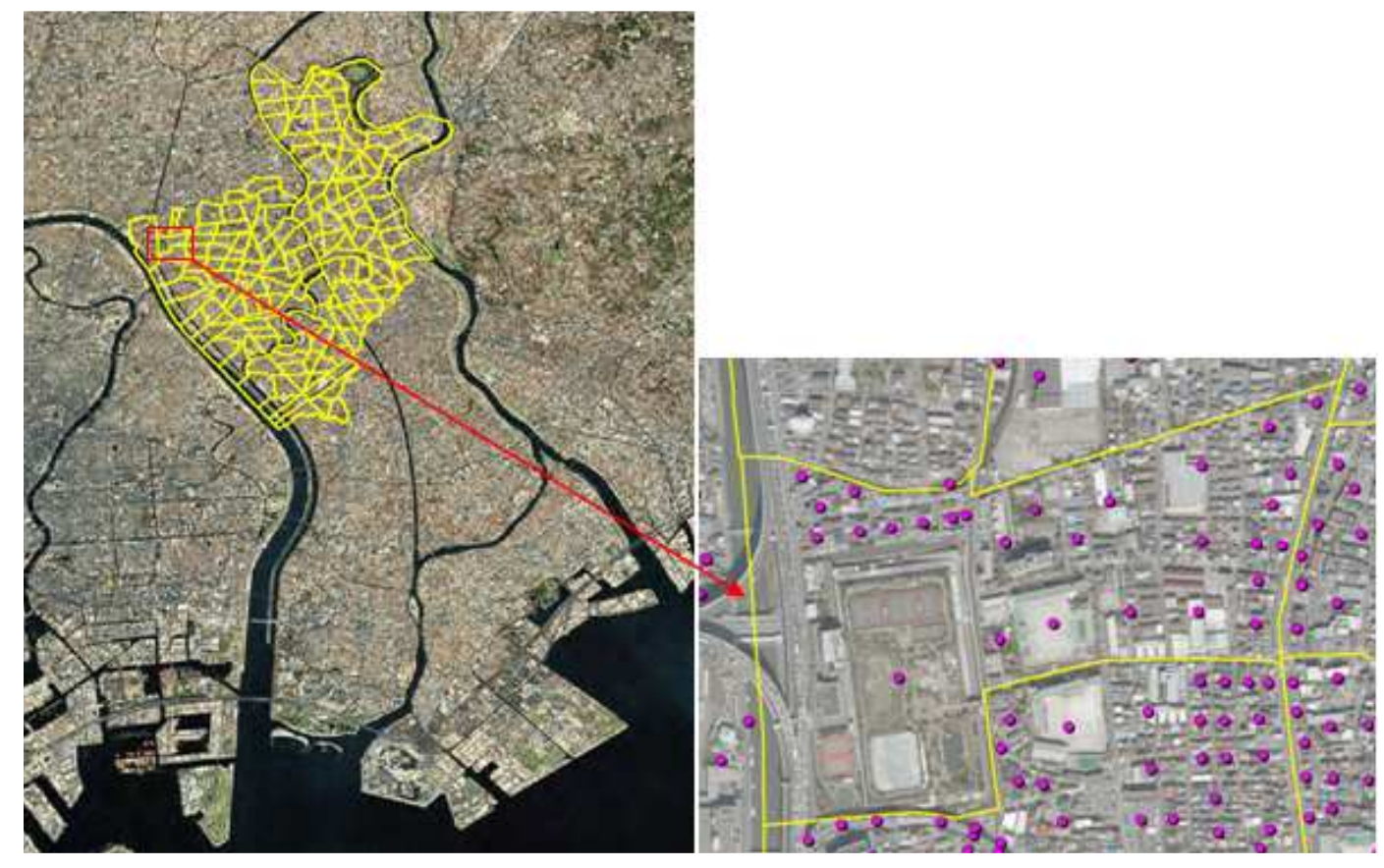

Fig. 5. GIS files in Japanese address system. Left: Cho/Chome boundaries in Katsushika Ward; Right: Gaiku points in a selected Cho/Chome (adapted from National Statistics Center, National and Regional Planning Bureau).

\subsection{Integration of processed location reference and census data sets}

The Gaiku level location reference data sets with flood depth values were then integrated with the 2005 census data. Census data contains the number of households in each Cho/Chome area broken down by building type: detached houses, terrace houses and apartments. For our study we only extracted figures for detached houses, terrace houses and apartments up to two stories. We assume that mainly low-rise buildings would be damaged in flood events, although we are aware that the lower levels of high-rise buildings are also at risk. High-rise buildings were excluded from consideration since the source data was unable to specify the number of households in the bottom floors of high-rise buildings; moreover, an unknown proportion of these would be commercial premises.

The extracted census figures for individual Cho/Chome areas were allocated to each Gaiku-level location reference point by distributing the census value evenly over the number of Gaiku location reference points in one Cho/Chome. The number of households at risk of inundation in each scenario was identified after aggregating the figures for each city/town/ward in the integrated data sets. Only depth levels in excess of $0.45 \mathrm{~m}$ were considered in this study as general insurers effectively treat above-floor inundation as beginning at this height above ground level. We note that the Building Standard Act of Japan (http://law.e-gov.go.jp/htmldata/ S25/S25SE338.html) specifies that floor elevation for general residential buildings be at least $0.45 \mathrm{~m}$ above ground level for reasons of moisture prevention.

\subsection{Insurance loss estimation}

In order to estimate insurance losses, the following insurance market data for residential buildings and contents have been adopted in this study:

- average insured amount for buildings per household by fire insurance policies - 23.74 million JPY;

- average insured amount for contents per household in fire insurance policies - 5.41 million JPY;

- insurance penetration (Non-life fire) - 64.3\%;

- proportion of comprehensive fire insurance policies that include flood cover $-71.8 \%$;

- reduced indemnity (maximum recovery of damage) for flood payouts - up to $70 \%$ of the insured amount depending on the damage ratio.

To determine the damage ratio, we employ the stagedamage functions of Dutta et al. (2003). These authors produced separate but almost identical stage damage functions for wooden and reinforced concrete structure buildings (Fig. 3 in Dutta et al., 2003), in which the damage ratio, $Y$, can be parameterised as a simple function of above floorlevel water depth, $X$ : 
$Y=0.2 \times X \quad$ if $X \leq 3 \mathrm{~m}$

$Y=0.6 \quad$ if $X>3 \mathrm{~m}$

Dutta et al. (2003) also provide loss functions for residential contents (Fig. 3 in Dutta et al., 2003) and in a similar vein we parameterise these as:

$Y=0.25 \times X \quad$ if $X \leq 3 \mathrm{~m}$

$Y=0.75 \quad$ if $X>3 \mathrm{~m}$

The average insured amounts for buildings and contents per household were acquired from the statistics figures published by the Non-Life Insurance Rating Organization of Japan (2009). Their total insured amounts for buildings and contents were averaged by number of policies, and the amounts for policies that contain both were weighted to obtain the total average values. The fire insurance penetration ratio and its proportion of comprehensive policies were confirmed in research conducted by the Japan Institute of Construction Engineering (2003).

In insurance parlance, a reduced indemnity means that the maximum payout on an insurance claim is limited by preset conditions depending on the damage ratio $(Y)$. An overview of comprehensive fire insurance policies for residential properties (The General Insurance Association of Japan, 2011) revealed that the payout structure can be broken down into the following three categories, depending upon the damage ratio. If $(Y)$ is:

- $30 \%$ or greater of the insured value of the property;

- less than $30 \%$, but equal or greater than $15 \%$ of the insured value; or

- less than $15 \%$ of the insured value.

Then the insurance payouts for these categories vary respectively:

- Insured amount $\times(Y) \times 70 \%$

- Insured amount $\times 10 \%$, but limited to 2 million JPY

- Insured amount $\times 5 \%$, but limited to 1 million JPY

In estimating insurance losses, our study adopts the above payout structures, and assumes that the insurance value (as assessed by an insurance company) and insured amount (as assessed by the property owner) for each property are the same.

\subsection{Summary of key assumptions and calculation steps}

For the ease of the reader, we now briefly summarise the key assumptions and calculation steps that comprise the following:

(a) Water depth is taken as constant across each Gaiku.

(b) Damage ratio ( $Y$, at Gaiku level) is taken as a simple function of water depth above ground level (less $0.45 \mathrm{~m}$ ) with maximum values of $60 \%$ for building and $75 \%$ for contents.

(c) Numbers of households per Gaiku are determined from census counts at $\mathrm{Cho/Chome} \mathrm{resolution,} \mathrm{divided} \mathrm{by} \mathrm{the}$ number of Gaiku per Cho/Chome.

(d) Insured amounts per household are taken as 23.74 million JPY for building and 5.41 million JPY for contents.

(e) Non-life fire insurance policies are held by $64.3 \%$ of households.

(f) $71.8 \%$ of insured households are assumed to have comprehensive flood cover.

On the basis of these assumptions and the insurance policy conditions given earlier, typical insurance payouts follow as:

If $Y$ (damage ratio) is $\geq 30 \%$ of the insured value of the property, then

insurance payout per Gaiku $=(\mathrm{c}) \times(\mathrm{d}) \times(\mathrm{e}) \times(\mathrm{f}) \times$ (b) $\times 70 \%$.

If $Y$ is $\geq 15 \%$ and $<30 \%$ of the insured value, insurance loss per Gaiku $=(c) \times(d) \times(e) \times(f) \times 10 \%$.

If $Y$ is $<15 \%$ of the insured value, then the insurance loss per Gaiku $=(c) \times(d) \times(e) \times(f) \times 5 \%$

Lastly, the total insurance loss for residential households is calculated by summing across Gaiku for the entire study area per flood scenario.

\section{Results and discussion}

\subsection{Estimated numbers of households inundated}

Table 1 compares the number of households estimated to be inundated above floor level in each of the six major flood scenarios examined. In five out of the six scenarios, our study found smaller numbers of affected households than CDPC2010. Only for the R118k5 scenario did we find larger numbers, but the actual numbers of households in this case are relatively small. Possible reasons for the larger numbers for this scenario compared with the CDPC2010 report are 
the large proportion of households living in low-rise buildings in the affected city $(93.3 \%)$. The differing ages of the various source data sets - the census data is from 2005 while Gaiku centroids are from 2009 - and other geographi$\mathrm{cal} / \mathrm{demographic}$ changes such as city development and land readjustments that may have occurred during the intervening period also contribute additional uncertainty in the numbers.

The R136k0 scenario has a significantly larger number of households affected than other scenarios. This is in line with the CDPC2010, but a large discrepancy exists between that report and our result. The difference can perhaps be explained by the relatively low proportions of low-rise buildings in the two main contributing areas: Tokyo Metropolitan Area $(50.57 \%)$ and Saitama Prefecture $(74.42 \%)$. These two prefectures represent $99.99 \%$ (36.65\% and $63.34 \%$, respectively) of the total households inundated above floor level in this scenario. However, CDPC2010 contains insufficient detail to investigate this difference more fully.

\subsection{Estimated insurance loss for residential buildings and contents}

Table 2 presents the loss estimates for each of the six flooding scenarios. The estimates of insurance payout for the six scenarios are not proportional to numbers of affected households in Table 2 due to differences in the numbers of households impacted in each Gaiku, spatial variations in the depth of flooding and the non-linearity of the payout structure as explained in Sect. 3.3. The R136k0 scenario is the closest to the flood event caused by Typhoon Kathleen and the only one for which the modelled flood reaches the eastern side of the Tokyo Metropolitan Area after passing through the densely populated eastern part of Saitama.

Our maximum scenario insured loss is 956432 million JPY for R136k0, the scenario that most closely mimics that arising from Typhoon Kathleen. The average of all six scenarios is 205054 million JPY. All of these figures are considerably less than the estimate of total economic loss of 34 trillion (34000 000 million) JPY given by the Tone River Upstream Office (2011). However, this official estimation purportedly includes losses to a very broad range of items such as general assets, agricultural crops and so on, but its breakdown is unknown.

The modelled loss for R136k0 exceeds the largest known historical insured loss recorded since 1970 in Japan of US\$8899 million ( $\sim 828$ billion JPY) caused by Typhoon No. 19 in 1991 (Swiss Re, 2010). While serving to illustrate that a R136k0 event would be a significant loss event for the Japanese insurance industry, the losses cannot be strictly compared as the Swiss Re figures have only been adjusted for inflation and not for changes in population and wealth in addition to inflation as per Pielke and Landsea (1998), Pielke et al. (2008) and Crompton and McAneney (2008). The Swiss Re figure for Typhoon No. 19 does includes losses from all lines of business, including business interruption.
Globally, for nine out of the ten most costly flood events since 1980, the proportion of insured losses to the total estimated economic losses has been around $6 \%$ or lower, including $5 \%$ for the floods in the US (Iowa, Illinois, Indiana, Kansas, Michigan, Minnesota, Missouri, Wisconsin) in 2008 and $0.7 \%$ for floods in Italy in 1994 (Munich Re, 2011). Our results with the maximum proportion of $3 \%$ (for scenario $\mathrm{R} 136 \mathrm{k} 0$ ) are in line with this loss experience, despite only accounting for damage to residential property.

The ARI of the rainfall following Typhoon Kathleen is estimated to be on the order of $200 \mathrm{yr}$ (Cabinet Office, 2006). However, it is difficult to put an ARI on the modelled loss since we cannot know the relative or joint probability of the different loss scenarios shown in Table 2. It is possible that more than one of these scenarios could occur simultaneously or levee failure at one point might lower water levels downstream, and avoid a failure at all other points. At this juncture, the ARI of the loss cannot be determined.

\subsection{Further analyses on R136k0 and implications for mitigation and emergency management}

Spatial differences in modelled losses for those municipalities impacted by a R136k0-like flood scenario are important, because they closely reflect exposure level of local areas, a major component of damage estimation (Fedeski et al., 2007), to the flood risk. These differences arise from factors such as differing numbers of households occupying low-rise buildings, the extent of flooding and the damage ratio dictated by corresponding flood depths. Saitama Prefecture, for example, comprises 21 affected municipalities and the simple ratio of low-rise households, i.e. those households considered explicitly in our study, to the total number of households is very different across these municipalities. For example, Matsubushi Town's ratio is the highest proportion at $98 \%$, while Misato City has the lowest at $57 \%$.

The proportion of low-rise households with above floor flooding $(0.45 \mathrm{~m})$ to total households in Kurihashi Town is the highest ( $92 \%$ of households), while Hasuda City has the lowest with only $0.07 \%$. Washimiya Town shows the highest proportion of low-rise households with above floor flooding $(100 \%)$ to total number of low-rise households, while Hasuda City has the lowest (Fig. 6).

These proportions and numbers of households need to be considered when developing countermeasures for local areas, because the risk for each area is different. For example, low-rise households in Misato City are only $57 \%$ of the total, the lowest amongst the relevant 21 municipalities, while almost all $(99 \%)$ of these are subject to above floor flooding $(0.45 \mathrm{~m})$. Given that most low-rise households in this city may experience above floor inundation, countermeasures against flood risk should focus on the entire group of low-rise households.

In contrast, Shobu Town, which has a high proportion of low-rise households $(97 \%)$, has relatively small percentages 
Table 1. Estimated numbers of households inundated above floor level. Proportions are rounded off to the nearest $\%$ point.

\begin{tabular}{lrrr}
\hline \multirow{2}{*}{ Scenario } & CDPC2010 & \multicolumn{2}{c}{ This study } \\
\cline { 3 - 4 } & & $\begin{array}{c}\text { Households } \\
\text { (1\&2 Stories Only) }\end{array}$ & $\begin{array}{r}\text { Proportion of } \\
\text { CDPC2010 (\%) }\end{array}$ \\
\hline R182k5 & 3100 & 2836 & 91 \\
R136k0 & 680000 & 459676 & 68 \\
R118k5 & 16000 & 18698 & 117 \\
L172k5 & 6200 & 3526 & 57 \\
L159k5 & 26000 & 23893 & 92 \\
L132k0 & 31000 & 27723 & 89 \\
\hline
\end{tabular}

Table 2. Estimated insurance loss for residential buildings and contents (unit: million JPY).

\begin{tabular}{ccrr}
\hline Scenario & Item & $\begin{array}{r}\text { Insurance } \\
\text { Loss }\end{array}$ & $\begin{array}{r}\text { Total Insurance } \\
\text { Loss }\end{array}$ \\
\hline \multirow{2}{*}{ R182k5 } & Building & 1861 & 2382 \\
& Contents & 521 & \\
R136k0 & Building & 729976 & 956432 \\
& Contents & 226456 & \\
R118k5 & Building & 60436 & 77843 \\
& Contents & 17407 & \\
L172k5 & Building & 3791 & 5007 \\
& Contents & 1216 & \\
L159k5 & Building & 69783 & 89994 \\
& Contents & 20211 & \\
L132k0 & Building & 75799 & 98667 \\
& Contents & 22868 & \\
\hline
\end{tabular}

of low-rise households with above floor flooding (12\% and $13 \%$ for the ratio to the total households and to the total low-rise households respectively), despite its proximity to the levee breach point. These low proportions of above floor inundation may be related to a flood extent that only covers a small part of the town possibly due to its ground elevation levels. In this case, local countermeasures for this town should be developed in a different way from Misato City, focusing on the north and east parts of the town, where inundation is anticipated.

These spatial differences in flood risk can be considered in combination with other relevant factors such as the elapsed time after the commencement of outflow, population size and density. For instance, an evacuation plan in Misato City can be considered to maximise the potential large number of high-rise buildings in the city, although it is of course important to take other elements such as the communication/transport methods during the flood into account as well.

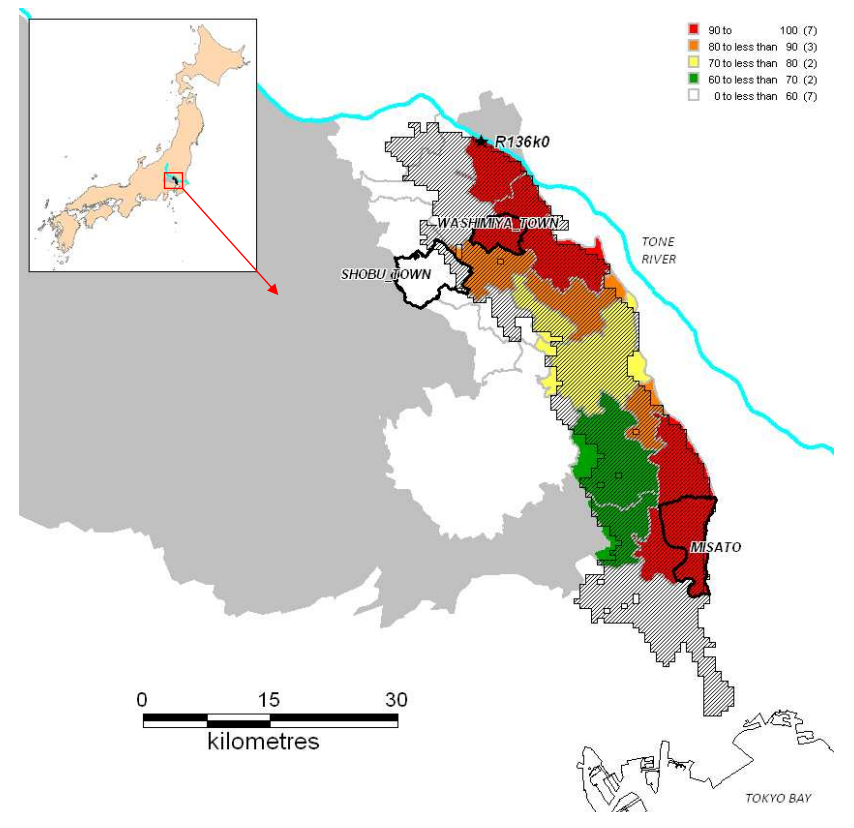

Fig. 6. Proportion of low-rise households with water depths greater than $0.45 \mathrm{~m}$ compared with total low-rise households Star: Leveebreak point (136 km upstream on the right levee), Dark Gray: Other municipalities in Saitama; Shaded polygon: Flood extent of the R136k0 scenario (adapted from Tone River Upstream Office, National Statistics Center, National and Regional Planning Bureau, ESRI Japan Corporation).

Various incentive policies, practical evacuation plans and risk-informed development of infrastructure can all be evaluated based on these factors.

\section{Limitations}

A number of factors contribute uncertainties in our loss estimates. First, the rather coarse resolution of the flood depth grids (approximately $500 \mathrm{~m} \times 500 \mathrm{~m}$ ) means that we have assumed one uniform depth level for all Gaiku points 
located within a rectangular area of approximately $0.25 \mathrm{~km}^{2}$. Nonetheless, our results should be considered conservative, in the sense that we adopted the greatest depth value within each grid cell.

Further, the asynchrony and the structural differences of the Gaiku level location reference data from 2009 and the census data for the Cho/Chome level from 2005 leave room for improvement. Clearly it would be better to have data from a common date and purpose, but we have chosen to use the data in the public domain.

Thirdly, excluding apartments higher than two stories also constrains the number of inundated households, because the first and second floors of those buildings are also at risk to inundation. However, this feature would be offset to a certain extent, since many of the low-rise building households such as those on the second floor would avoid damage if the corresponding flood depth level was low.

Our study has only considered residential buildings and contents, ignoring losses from any other lines of business such as commercial, industrial and motor. Data limitations do not allow us to explore this loss contribution from these other lines of business, but it is clear that the total insured losses will be much greater than our modelled figures once claims for these are included. The true economic losses are likely to be many times the insured figure.

Lastly, we note that there are other types of fire insurance available in Japan, such as the latest-edition fire insurance and content coverage for apartment residents, in addition to the comprehensive policies that we have considered. Some of the recent editions provide $100 \%$ indemnity for flood damages, while the apartment-type content covers often fully exclude such damage. However, those policies are very difficult to take into account precisely due to their varying conditions, and adopting figures based only on comprehensive policies should give a reasonably reliable first-order estimate considering their high level of penetration in the Japanese market.

\section{Conclusions}

By integrating different data sets in a GIS framework, we have modelled insurance losses from the flooding of residential property for six different flooding scenarios on the Tone River. The magnitude of the modelled losses reflects the likely distribution of flood depths, building heights and population. The largest modelled loss for a Typhoon Kathleentype scenario, given levee failure in a similar location, is almost 1 trillion JPY (\$US 12.5 billion). The total insured losses may be an order of magnitude twice this value (Roche et al., 2011) and economic losses greater again.

The 1 trillion JPY estimate could be either an over- or under-estimate of the actual insured loss for residential properties, depending upon exactly where and at how many locations the Tone River levee system broke its banks. We are unable to give an ARI for the modelled losses, although the rainfall event that might give rise to the flooding and levee breakage at one or more points in the system has been accorded a 1:200 yr event.

Locally explicit characteristics associated with the flood risk are also an important aspect to be examined in risk assessment and damage mitigation. What this study does clearly demonstrate is the power of GIS used to examine such spatial differences to evaluate scenario losses. Such information is also needed to support risk-informed policy decisions with respect to land-use planning decisions, planning for emergency evacuation and to provide a lower bound cost against which the cost of mitigation measures can be assessed. The data integration approach that we have used here has the potential to yield further efficiencies in risk assessment and in evaluating locally-relevant mitigation measures.

Acknowledgements. The authors would like to thank Yoshitomo Saeki, Kazushige Kobayashi and Katsuyuki Uchikura from the Tone River Upstream Office for providing their flood-scenario data sets. We are also grateful to Toshitaka Katada from Gunma University for his support and advice. We acknowledge the officers from local governments of Ibaraki, Saitama and Tokyo Prefectures, including Adachi, Edogawa, Katsushika, Kazo, Koga, Kuki and Misato Cities, Nobuo Nonaka from the flood prevention group in the Hanyu region and Kazuo Okayama from the Foundation of River and Basin Integrated Communications for sharing their knowledge and experience with us and Luke Johnston and Atsuhiro Dodo from Swiss Reinsurance for suggesting this research problem. Comments from reviewers helped improve our manuscript.

Edited by: F. Luino

Reviewed by: two anonymous referees

\section{References}

Bouwer, L. M.: Have disaster losses increased due to anthropogenic climate change?, B. Am. Meteorol. Soc., January, 39-46, 2011.

Cabinet Office, Government of Japan: Report on 1947 Typhoon Kathleen, available at: http://www.bousai.go.jp/jishin/chubou/ kyoukun/rep/1947-kathleenTYPHOON/ (last access: 10 May 2011), 2006.

Central Disaster Prevention Council, Cabinet Office, Government of Japan: The expert panel report on the countermeasures against large-scale flood disaster, available at: http://www.bousai.go.jp/ jishin/chubou/suigai/100402/100402_shiryo_2.pdf (last access: 11 May 2011), 2010.

Crompton, R. P. and McAneney, K. J.: Normalised Australian insured losses from meteorological hazards: 1967-2006, Environ. Sci. Policy, 11, 371-378, 2008.

Downton, M. W. and Pielke Jr., R. A.: How Accurate are Disaster Loss Data? The Case of U.S. Flood Damage, Nat. Hazards, 35, 211-228, doi:10.1007/s11069-004-4808-4, 2005.

Dutta, D., Herath, S., and Musiake, K.: A mathematical model for flood loss estimation, J. Hydrol., 277, 24-49, doi:10.1016/S0022-1694(03)00084-2, 2003.

Fedeski, M. and Gwilliam, J.: Urban sustainability in the presence of flood and geological hazards: The development of a GIS- 
based vulnerability and risk assessment methodology, Landscape Urban Plan., 83, 50-61, doi:10.1016/j.landurbplan.2007.05.012, 2007.

Forte, F., Strobl, R. O., and Pennetta, L.: A methodology using GIS, aerial photos and remote sensing for loss estimation and flood vulnerability analysis in the Supersano-RuffanoNociglia Graben, southern Italy, Environ. Geol., 50, 581-594, doi:10.1007/s00254-006-0234-0, 2006.

Japan Institute of Construction Engineering: Research into future direction of water control measures: Deliberation of future action from the view point of flood insurance system, available at: http://www.jice.or.jp/jishu/t1/pdf/jice104001_040112. pdf (last access: 16 June 2011), 2003.

Kanto Regional Development Bureau, Ministry of Land, Infrastructure, Transport and Tourism: http://www.ktr.mlit.go.jp/river/ bousai/river_bousai00000007.html, last access: 10 May 2011.

Kondo, A.: Interpretation of Disaster Potential by Remote Sensing and Geographic Information, Journal of Japanese Association of Hydrological Sciences, 35, 111-117, 2005.

Luino, F., Biddoccu, M., Cirio, C. G., Agangi, A., Giulietto, W., Godone, F., and Nigrelli, G.: Application of a model for the evaluation of flood damage, GeoInformatica, Springer Ed, 13 339353, doi:10.1007/s10707-008-0070-3, 2009.

Ministry of Internal Affairs and Communications: available at: http: //law.e-gov.go.jp/htmldata/S25/S25SE338.html, last access: 25 July 2011.

Merz, B., Kreibich, H., Schwarze, R., and Thieken, A.: Review article "Assessment of economic flood damage", Nat. Hazards Earth Syst. Sci., 10, 1697-1724, doi:10.5194/nhess-10-16972010, 2010.

Munich Re: Significant natural catastrophes 1980-2011: 10 costliest floods worldwide ordered by overall losses, available at: http://www.munichre.com/app_pages/www/@res/ pdf/NatCatService/significant_natural_catastrophes/2011/

NatCatSERVICE_significant_floods_eco_june2011_en.pdf (last access: 27 July 2011), 2011.

Nakajima, H.: The current of technology for river dike, Kasen, January 2004 Edn., 17-28, 2004.

National Research Institute for Earth Science and Disaster Prevention: available at: http://dil.bosai.go.jp/workshop/02kouza_jirei/ s01kanto/tonekouzui.htm, last access: 10 May 2011.

Non-Life Insurance Rating Organization of Japan: Statistics Compiled by Non-Life Insurance Rating Organization of Japan, Fiscal 2009, available at: http://www.nliro.or.jp/disclosure/toukei/ index.html (last access: 15 June 2011), 2009.
Okazaki, T.: Business continuity management based on a potential flooding - Flood simulation for the Edo River, TRC EYE Vol. 245, available at: http://www.tokiorisk.co.jp/risk_info/up_file/ 200905291.pdf (last access: 27 July 2011), 2009.

Pielke Jr., R. A. and Landsea, C. W.: Normalized Hurricane Damages in the United States: 1925-1995, Weather Forecast., 13, 621-631, 1998.

Pielke Jr., R. A., Gratz, J., Landsea, C. W., Collins, D., Saunders, M., and Musulin, R.: Normalized hurricane damage in the United States: 1900-2005, Nat. Hazards Rev., 9, 29-42, 2008.

Roche, K., McAneney, K. J., and K. Chen: The Great Australian Flood of 1954: cost of a recurrence, Weather, Climate Soc., in review, 2011.

Saito, T.: History of Passageway Changing Works and the Present Fig. of the Middle Stream of Tone River, Josai University bulletin, March 2006 Edn., 29-42, 2006.

Sanders, R., Shaw, F., MacKay, H., Galy, H., and Foote, M.: National flood modelling for insurance purposes: using IFSAR for flood risk estimation in Europe, Hydrol. Earth Syst. Sci., 9, 449456, doi:10.5194/hess-9-449-2005, 2005.

Scawthorn, C., Blais, N., Seligson, H., Tate, E., Mifflin, E., Thomas,W., Murphy, J., and Jones, C.: HAZUS-MH Flood Loss Estimation Methodology, I. Overview and Flood Hazard Characterization, Nat. Hazards Rev., 7, 60-71, 2006a.

Scawthorn, C., Flores, P., Blais, N., Seligson, H., Tate, E., Chang, S., Mifflin, E., Thomas,W., Murphy, J., Jones, C., and Lawrence, M.: HAZUS-MH Flood Loss Estimation Methodology. II. Damage and Loss Assessment, Nat. Hazards Rev., 7, 72-81, $2006 \mathrm{~b}$.

Swiss Re: Floods - an insurable risk?, available at: http://media. swissre.com/documents/floods_insurable_risk_en.pdf (last access 11 May 2011), 2007.

Swiss Re: Natural catastrophes and man-made disasters in 2009 , Sigma No. 1, Zurich, 2010.

The General Insurance Association of Japan: available at: http://www.sonpo.or.jp/protection/disaster/flood/0011.html, http://www.sonpo.or.jp/useful/insurance/kasai/point.html, http://www.sonpo.or.jp/archive/statistics/disaster/typhoon.html, last access: 27 July 2011.

Tone River Upstream Office: available at: http://www.ktr.mlit. go.jp/tonejo/shoukai/1-1.htm, http://www.ktr.mlit.go.jp/tonejo/ saigai/sinsuisoutei/shin_top.htm, last access: 10 May 2011. 